\begin{tabular}{r|l|l|l}
$\begin{array}{c}\text { Case Reports in } \\
\text { Oncology }\end{array}$ & $\begin{array}{l}\text { Case Rep Oncol 2010;3:334-338 } \\
\text { DOl: 10.1159/000320939 }\end{array}$ & $\begin{array}{l}\text { Published online: } \\
\text { September 14, 2010 }\end{array}$ & $\begin{array}{l}\text { O 2010 S. Karger AG, Basel } \\
\text { ISSN 1662-6575 } \\
\text { www.karger.com/cro }\end{array}$ \\
\hline
\end{tabular}

\title{
Metastatic Small Intestinal Cancer of the Urinary Bladder
}

\author{
Teppei Morikawa $^{\mathrm{a}}$ Akiteru Goto $^{\mathrm{a}}$ Hiroaki Nishimatsu ${ }^{\mathrm{b}}$ \\ Masashi Fukayama ${ }^{a}$
}

Departments of aPathology and ' Urology, Graduate School of Medicine,

University of Tokyo, Tokyo, Japan

\section{Key Words}

Adenocarcinoma $\cdot$ Immunohistochemistry $\cdot$ Metastasis $\cdot$ Small intestinal cancer $\cdot$ Urinary bladder

\begin{abstract}
We report an extremely rare case of small intestinal cancer metastasized to the urinary bladder, presenting a urologic symptom. A 41-year-old man first presented with nausea, vomiting and abdominal pain. Based on the clinical diagnosis of jejunal cancer, he underwent a partial resection of the jejunum with lymph node dissection. The pathological diagnosis was moderately differentiated adenocarcinoma of the jejunum, pT4NO. Seventeen months after surgery, he presented with a gross hematuria. Computed tomographic scan showed wall thickening of the posterior wall of the urinary bladder. No tumor was found in other organs or lymph nodes. Based on histological and immunohistochemical analysis, the diagnosis of urinary bladder metastasis from jejunal adenocarcinoma was made. This is the first report of urinary bladder metastasis from small intestinal cancer. Although very rare, the possibility of metastatic small intestinal cancer should be considered in differential diagnosis in patients with adenocarcinoma involving the urinary bladder.
\end{abstract}

\section{Introduction}

Cancer of the small intestine is rare. While the small intestine constitutes $90 \%$ of the absorptive area of the gastrointestinal tract, malignant tumors of the colon and rectum are 50 times more common [1]. Common metastatic sites of small intestinal cancer are regional lymph nodes and liver [2]. We report an extremely rare case of solitary urinary bladder metastasis from small intestinal cancer, presenting a urologic symptom. 


\section{Case Report}

A 41-year-old man was admitted to the hospital because of nausea, vomiting and abdominal pain. While upper gastrointestinal endoscopy showed no significant finding, computed tomographic scan showed wall thickening of the upper small intestine. Fluoroscopic examination of the small intestine revealed a tumor mass in the jejunum 20 to $30 \mathrm{~cm}$ distal from the ligament of Treitz. Endoscopy of the small intestine with biopsy was performed and the tumor was diagnosed as adenocarcinoma. Large intestinal endoscopy showed no significant finding. He underwent a partial resection of the jejunum with lymph node dissection. The surgical specimen showed a $5.0 \times 4.5 \mathrm{~cm}$-sized tumor mass in the jejunum, obstructing the intestinal tract (ig. 1). The pathological diagnosis was moderately differentiated adenocarcinoma of the jejunum. The tumor invaded beyond the serosa of jejunum (pT4) without lymph node metastasis ( $\mathrm{pN} 0)$. He did not receive any adjuvant therapy and was followed up as an outpatient.

Seventeen months after surgery, he presented with a gross hematuria. Computed tomographic scan showed wall thickening of the posterior wall of the urinary bladder (fig. 2). No tumor was found in other organs or lymph nodes. Transurethral resection biopsy of the bladder tumor was performed, and the histological analysis showed enteric-type adenocarcinoma similar to the primary jejunal adenocarcinoma (fig. 3 ). No urothelial carcinoma component was found. Immunohistochemically, both the jejunal cancer cells and bladder cancer cells were positive for cytokeratin 20, CDX-2, p53 and carcinoembryonic antigen, and negative for cytokeratin 7 and thrombomodulin. The diagnosis of urinary bladder metastasis from jejunal adenocarcinoma was made. He was subsequently treated with chemotherapy (weekly paclitaxel) and a partial response was observed. However, he died from widespread metastases 25 months after the diagnosis of bladder metastasis.

\section{Discussion}

Metastatic urinary bladder tumors are rare, accounting for less than $2 \%$ of all bladder tumors [3], and are almost always associated with widely disseminated disease [4]. Most secondary bladder tumors represent direct invasion by tumors originating in an adjacent site, most commonly the female genital tract, prostate, colon and rectum [3]. A smaller proportion are metastases, most commonly from the skin (malignant melanoma), stomach, breast, or lung [3, 5, 6]. Melicow [3] examined 1,614 surgically resected bladder tumor cases and found 25 (1.5\%) metastatic tumors. The sites of origin were stomach (11 cases), breast (9 cases), lung ( 4 cases) and skin (1 case). Sheehan et al. [5] found 21 (0.4\%) metastatic bladder tumors in a series of 5,200 male autopsies in a single institution. The sites of origin were skin ( 8 cases), stomach ( 6 cases), lung ( 5 cases), pancreas ( 1 case) and colon ( 1 case). Although some other primary sites were reported $[6,7]$, to the best of our knowledge, this is the first report of urinary bladder metastasis from small intestinal cancer.

The distinction between a primary bladder adenocarcinoma and a secondary tumor involving the bladder is of great clinical importance in terms of staging, determining appropriate therapy, and assessing prognosis. Some immunohistochemical markers are reported to be of diagnostic value in the distinction between primary adenocarcinoma of the bladder and secondary intestinal adenocarcinoma [8-10]. Our immunohistochemical results on this case were compatible with secondary intestinal adenocarcinoma. The combination of clinical history, histological and immunohistochemical studies could confirm the diagnosis of bladder metastasis from small intestinal cancer in this case.

In the present case, small intestinal cancer metastasized only to the urinary bladder at the time of diagnosis, although most reported patients with metastatic bladder tumor have other sites of involvement $[4,5]$. In practice, knowledge of a history of tumor 


\begin{tabular}{r|l|l|l}
$\begin{array}{c}\text { Case Reports in } \\
\text { Oncology }\end{array}$ & $\begin{array}{l}\text { Case Rep Oncol 2010;3:334-338 } \\
\text { DOI: 10.1159/000320939 }\end{array}$ & $\begin{array}{l}\text { Published online: } \\
\text { September 14, 2010 }\end{array}$ & $\begin{array}{l}\text { O 2010 S. Karger AG, Basel } \\
\text { ISSN 1662-6575 } \\
\text { www.karger.com/cro }\end{array}$ \\
\hline
\end{tabular}

elsewhere and comparison with the original histology will establish the secondary nature of a bladder tumor in many cases. However, metastatic bladder tumor may be the first presentation [11]. Therefore, in cases where the histological findings do not clearly identify the bladder tumor as primary, investigation for tumor at other likely sites of origin is advisable. Particularly in case enteric-type adenocarcinoma involves the urinary bladder and no tumor is found by traditional large intestinal or upper gastrointestinal endoscopy, the possibility of small intestinal cancer should be considered and imaging studies should be performed.

In conclusion, we reported a previously unreported case of urinary bladder metastasis from small intestinal cancer. Although very rare, the possibility of metastatic small intestinal cancer should be considered in differential diagnosis in patients with adenocarcinoma involving the urinary bladder.

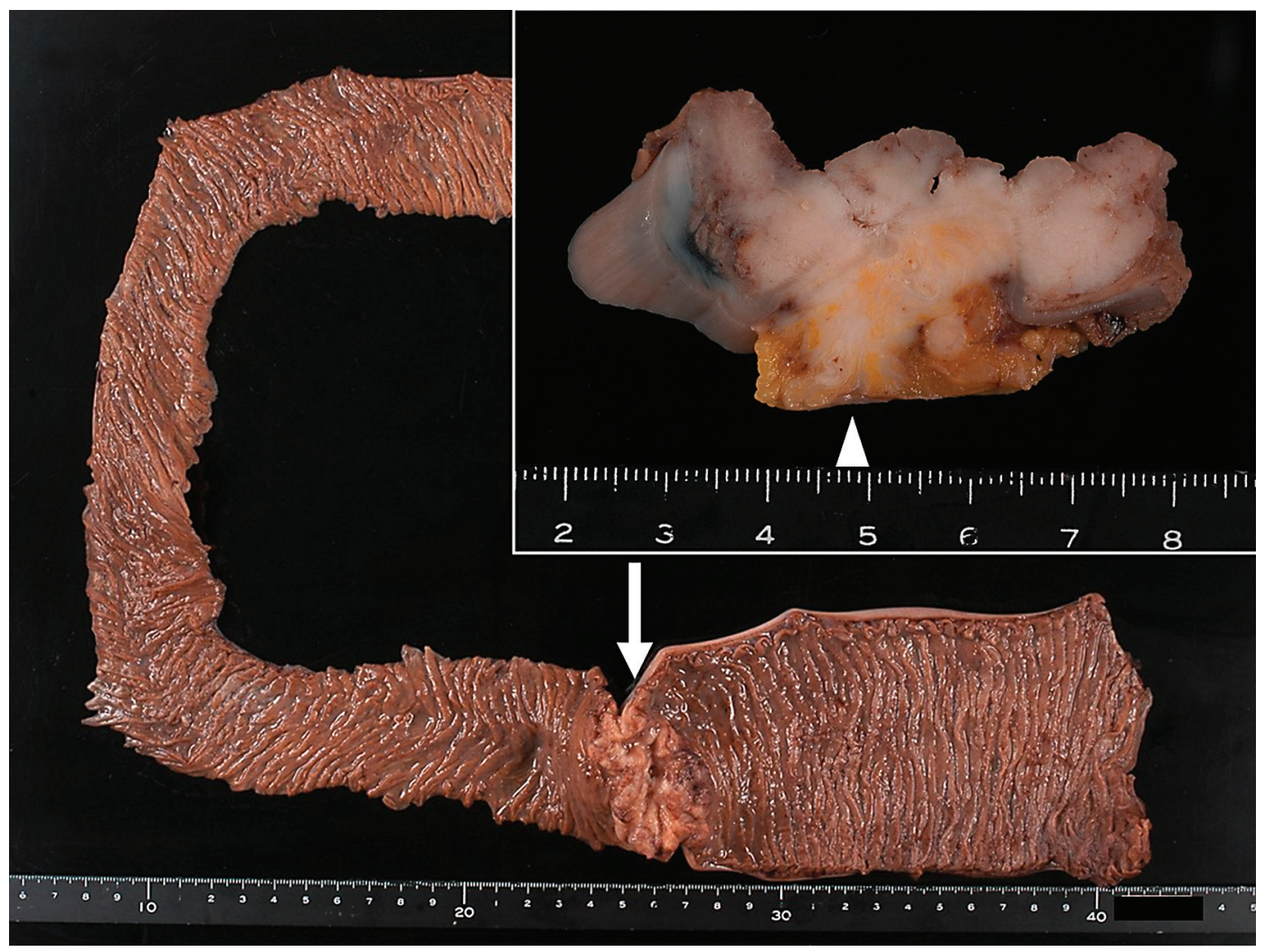

Fig. 1. Gross appearance of the jejunal tumor. A tumor mass with central ulceration is obstructing the intestinal tract (arrow). Inset: cut surface of the tumor. A whitish solid tumor invades beyond the muscularis propria of the jejunum to the mesentery (arrowhead). 


\begin{tabular}{c|l|l|l}
$\begin{array}{c}\text { Case Reports in } \\
\text { Oncology }\end{array}$ & $\begin{array}{l}\text { Case Rep Oncol 2010;3:334-338 } \\
\text { DOI: 10.1159/000320939 }\end{array}$ & $\begin{array}{l}\text { Published online: } \\
\text { September 14, 2010 }\end{array}$ & $\begin{array}{l}\text { I 2010 S. Karger AG, Basel } \\
\text { ISS 1662-6575 } \\
\text { www.karger.com/cro }\end{array}$ \\
\hline
\end{tabular}



Fig. 2. Computed tomographic scan shows wall thickening of the posterior wall of the urinary bladder (arrow).

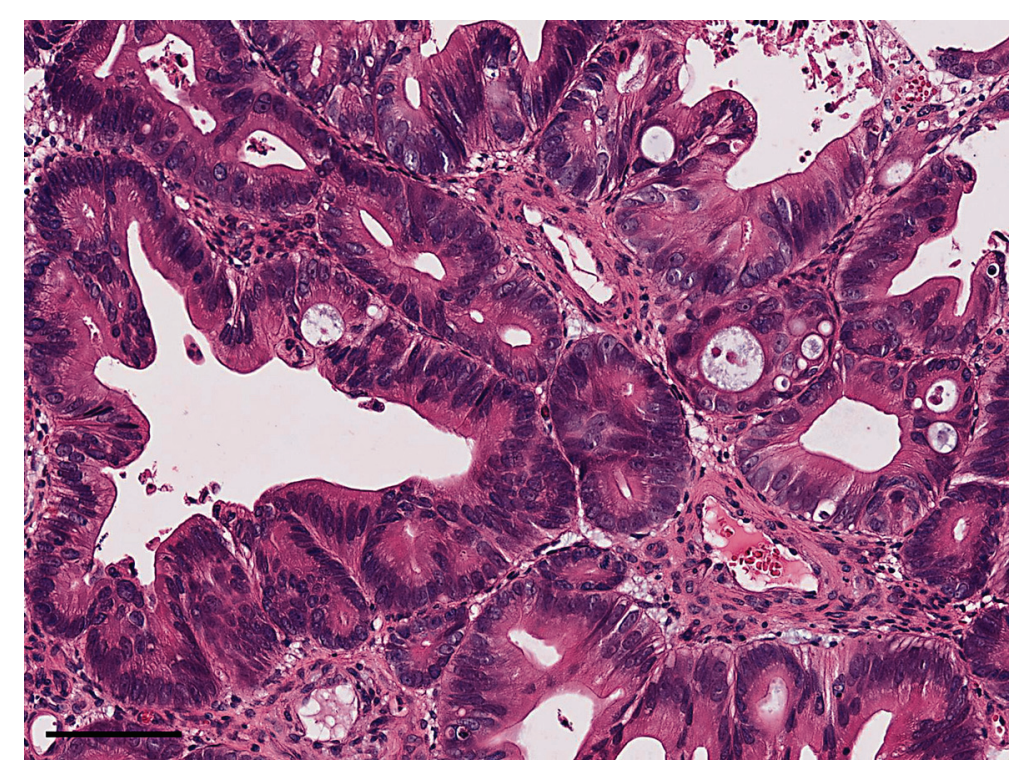

Fig. 3. Histological section of the bladder tumor shows enteric-type adenocarcinoma. Bar: $0.1 \mathrm{~mm}$.

\section{References}

1 Ross RK, Hartnett NM, Bernstein L, Henderson BE: Epidemiology of adenocarcinomas of the small intestine: is bile a small bowel carcinogen? Br J Cancer 1991;63:143-145.

2 Wu TJ, Yeh CN, Chao TC, Jan YY, Chen MF: Prognostic factors of primary small bowel adenocarcinoma: univariate and multivariate analysis. World J Surg 2006;30:391-398; discussion 399.

3 Melicow MM: Tumors of the urinary bladder: a clinico-pathological analysis of over 2,500 specimens and biopsies. J Urol 1955;74:498-521. 
4 Ganem EJ, Batal JT: Secondary malignant tumors of the urinary bladder metastatic from primary foci in distant organs. J Urol 1956;75:965-972.

-5 Sheehan EE, Greenberg SD, Scott R Jr: Metastatic neoplasms of the bladder. J Urol 1963;90:281-284.

6 Goldstein AG: Metastatic carcinoma to the bladder. J Urol 1967;98:209-215.

7 Morikawa T, Nishimatsu H, Kadono T, Homma Y, Fukayama M: Urinary bladder metastasis from extramammary Paget's disease in a patient with a past history of colon and gastric cancers. Pathol Int 2010;60:145-146.

8 Wang HL, Lu DW, Yerian LM, Alsikafi N, Steinberg G, Hart J, Yang XJ: Immunohistochemical distinction between primary adenocarcinoma of the bladder and secondary colorectal adenocarcinoma. Am J Surg Pathol 2001;25:1380-1387.

-9 Raspollini MR, Nesi G, Baroni G, Girardi LR, Taddei GL: Immunohistochemistry in the differential diagnosis between primary and secondary intestinal adenocarcinoma of the urinary bladder. Appl Immunohistochem Mol Morphol 2005;13:358-362.

-10 Suh N, Yang XJ, Tretiakova MS, Humphrey PA, Wang HL: Value of CDX2, villin, and alpha-methylacyl coenzyme A racemase immunostains in the distinction between primary adenocarcinoma of the bladder and secondary colorectal adenocarcinoma. Mod Pathol 2005;18:1217-1222.

11 Soon PS, Lynch W, Schwartz P: Breast cancer presenting initially with urinary incontinence: a case of bladder metastasis from breast cancer. Breast 2004;13:69-71. 